\title{
Electric Scissor Aerial Work Platform Solenoid Valve Research
}

\author{
Pan Guojun ${ }^{1}$ \\ Zhejiang Radio and Television University \\ Hangzhou,China \\ 185303952@qq.com
}

\begin{abstract}
Electric scissor aerial work platform generally uses hydraulic cylinder to lift. The decline solenoid valve is an important part of the entire hydraulic system, which usually installed in the bottom of the hydraulic cylinder. The main function is locking hydraulic cylinder to prevent the platform sinking due to its weight, protect workers safety. This paper first introduces its structure and working principle, and then does the experiments such as resistance pollutants, leakage, and a comprehensive analysis of the decline in the performance of the solenoid valve.
\end{abstract}

Keywords-component;solenoid valve; resistance pollutants; leak; test;

\section{INTRODUCTION}

Aerial work platform is the equipment which can lift works and load to the required height. It structure is composed of three parts: Part 1,that is the basic parts, the beam, walking wheels, steering structure and so on. Part 2, Work platform, a basket, guardrail and so on; Part 3: scissor part: it consists of links between chassis assembly and the platform assembly. The scissor arms though the hydraulic cylinder completes lifting operating, when stopped working platform, down solenoid valve lock to prevent the decline of the working platform due to weight and load. Due to the pure electric aerial work platform can self-propelled, electric start, Simple operation, and large work surface, has been widely used in municipal maintenance such as airports, docks, cargo transportation logistics center, large factories etc.

\section{STRUCTURES}

Decline solenoid valve is usually a two-way solenoid valve and its institutions as shown in Figure 1, 1 sleeve, 2 one-way valve plunger, 3 tapered needle, 4 spool, 5 coil, 6 Rod, 7 spring parts. When de-energized, the solenoid valve acts as a check valve, allowing flow to pass from (1) to (2), while blocking flow from (2) to (1). When energized, the poppet lifts to open the (2) to (1) flow path. In this mode, flow is also allowed from (1) to (2). Operation of Manual Override Option: To override, push button in, twist counterclockwise $180^{\circ}$ and release. In this position, the valve will remain open. To return to normal operation, push button in, twist clockwise $180^{\circ}$ and release.

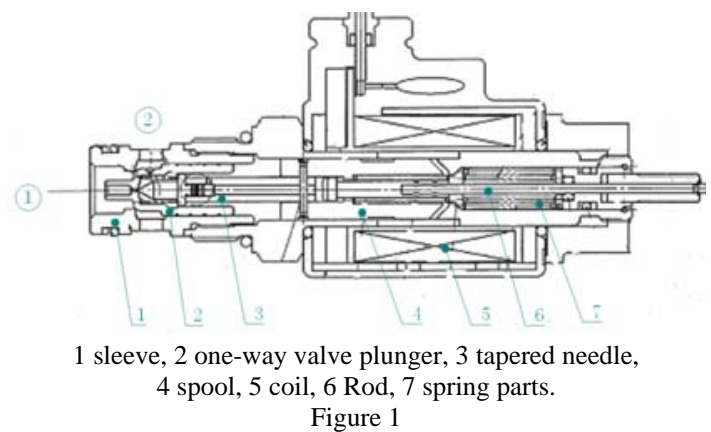

III. WORKING PRINCIPLE

First, the establishment of the movement model, and then lists the corresponding equation.

(1) Differential equations of motion

$$
P A-P_{1} A_{1}=m \frac{d^{2} x}{d t^{2}}+B \frac{d x}{d t}+F_{t}+K\left(x_{0}+x\right)+F_{f}
$$

$P, P_{1}$ :- Pressure on the spool upper and lower chambers

$A, A_{1}$ :- Area of the spool upper and lower chambers

$m:-$ Spool quality

$x$ :- Spool opening amount

$B$ :- viscous damping spool

$F_{t}:$-Transient flow force

$K, x_{0}$ :- The stiffness of the spring, the initial amount of compression Viscous damping spool

$F_{f}:-$ Friction

(2) The transient fluid power equation

$F_{t}=L C_{d} \pi D \sin a \sqrt{2 \rho P} \frac{d x}{d t}$

$L:-$ Spool damping length

$C_{d}$ :-The flow coefficient of the spool

$D$ :- Spool diameter

$a:-$ The taper angle of the spool

$\rho$ :-Fluid density

(3) Flow equation

$Q=C_{d} \pi D \sin a \sqrt{\frac{2\left(P-P_{1}\right)}{\rho}}$ 
$Q$ :- Inlet flow

(4) Current continuity equation

$Q-Q_{1}-A \frac{d x}{d t}=\frac{V}{\beta_{e}} \frac{d p}{d_{t}}$

$\beta_{e}$ :- The compression rate of the fluid

$V$ :- The volume of the spool

\section{Resistance Pollutants Experiment}

According to the operation cycle of the aerial vehicles, the operation resistance durability test of pollutants design shown in Figure 2, the electromagnetic coil loop shown in Figure 3, before the test first confirm the cleanliness of the fluid level is NAS12. Plc programming controls coil action, and the recorder records ports A and B ports pressure, the test photo shown in Figure 4, and the recorder records the results in Figures 5 and 6.
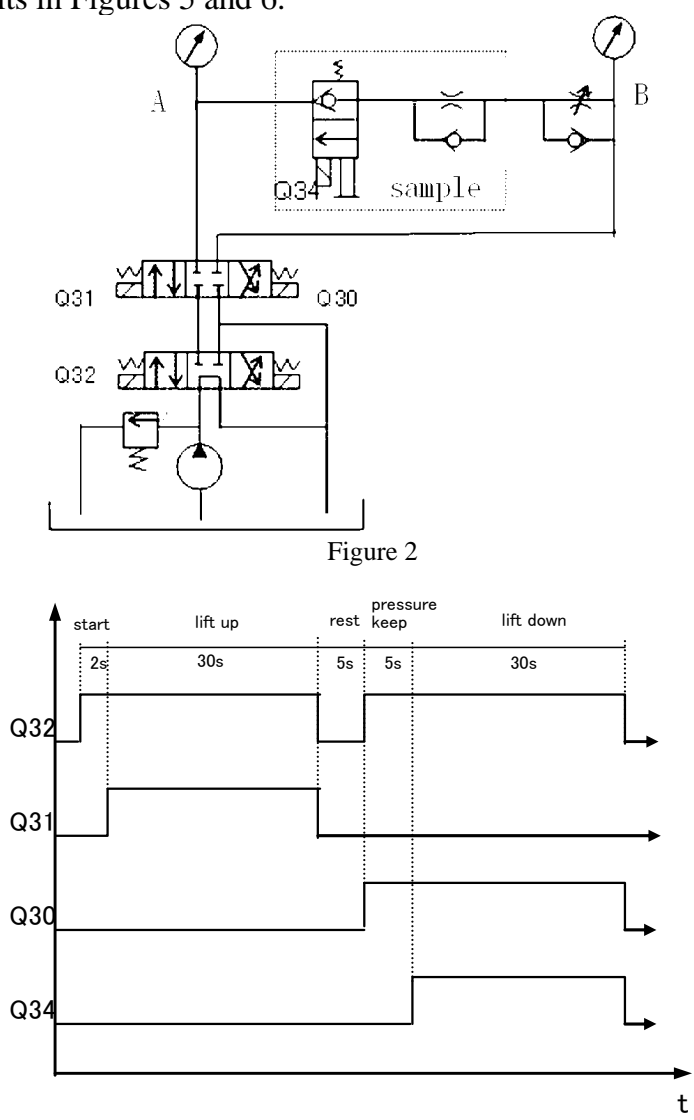

Figure 3

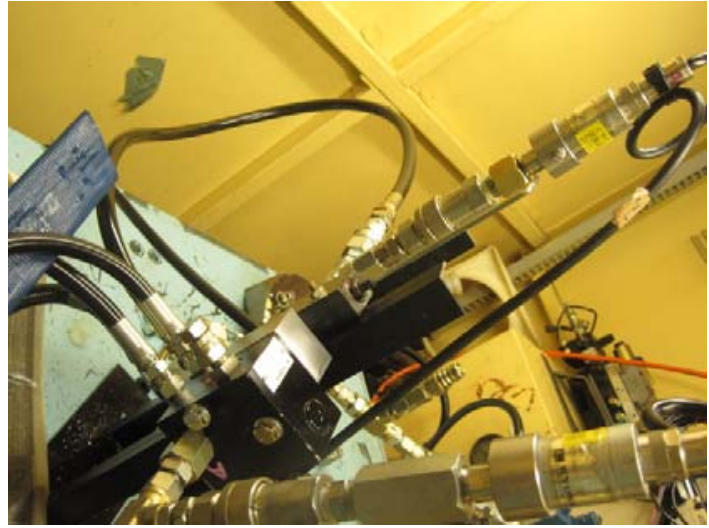

Figure 4

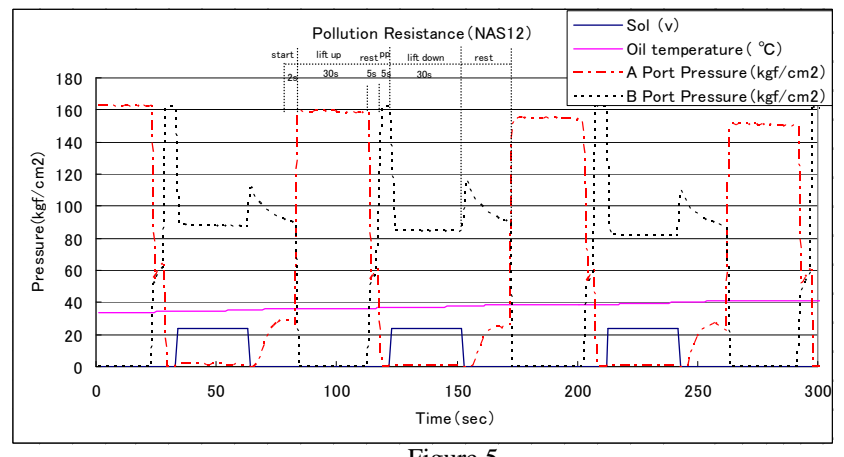

Figure 5

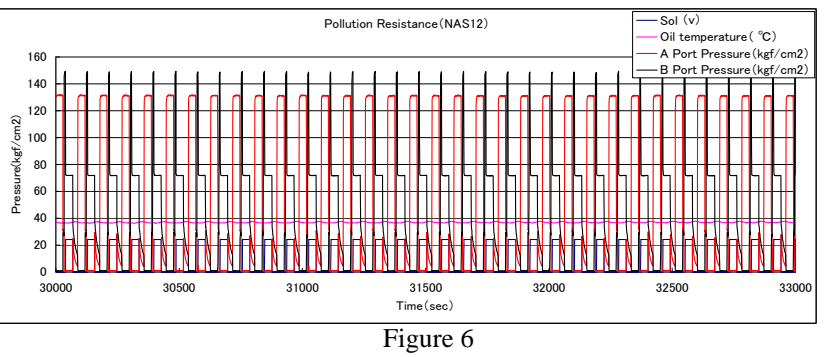

\section{LEAK EXPERIMENT}

The specific process for the leak test is relieving port A pressure sensor, and putting a Leak sensor under it, as shown in Figure 7.Its working principle is, there will be a signal when the fluid dripped. 175bar pressure is applied to the port $\mathrm{B}$, and recording the valve leaks, dropping a drop of fluid is about $0.05 \mathrm{ml}$, the record number of pulses can be converted to the amount of leakage. 


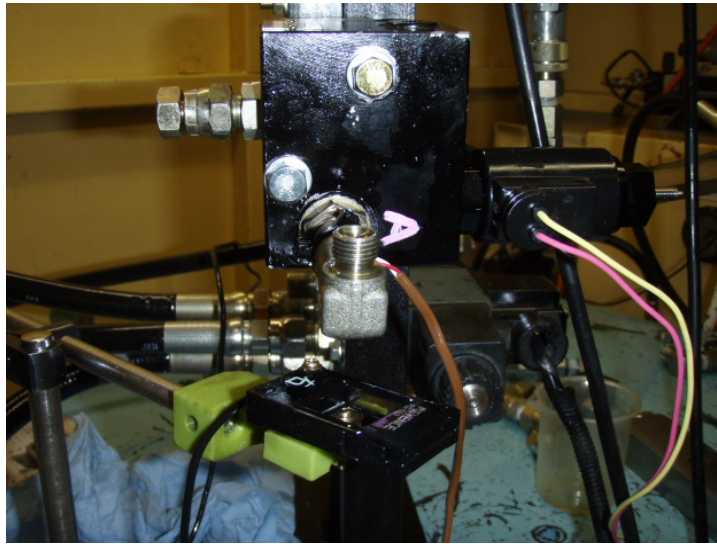

Figure 7

In order to ensure the reliability of the test, the valve resistant contaminants before and after the leak measurement, measured 3 times, respectively. Every drop of oil droplets fill in Table 1, and the value is converted to Figure 8.Our requirement is within 3 minutes the amount of valve leakage is less than $5 \mathrm{ml}$, leakage characteristic meets the requirements of the valve can be seen from Figure 9 .

Table 1
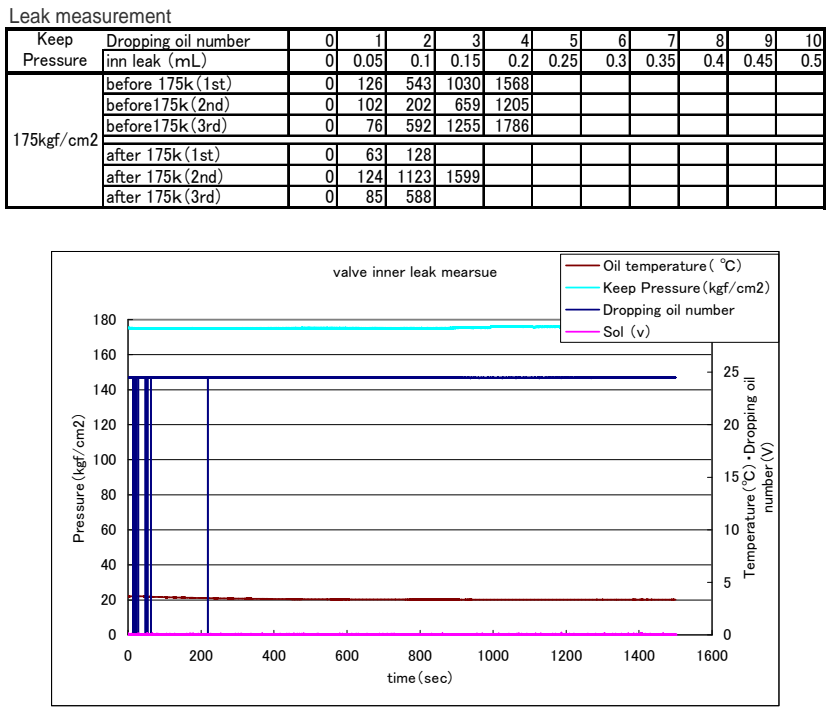

Figure 8

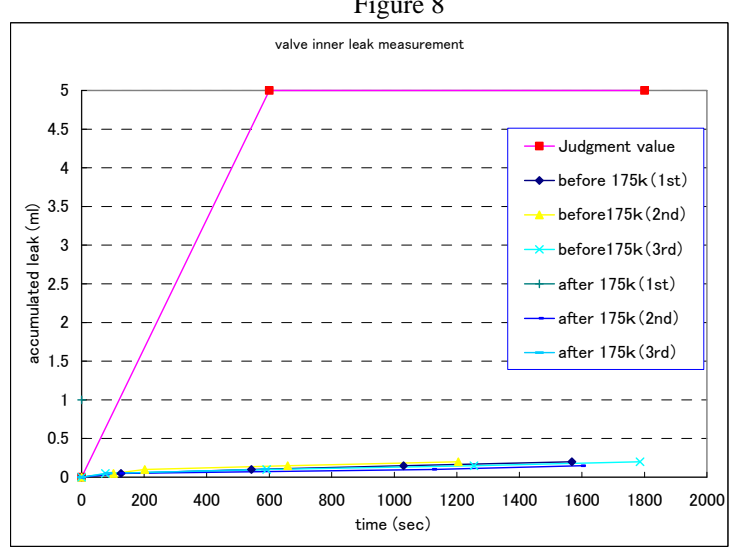

Figure 9

\section{CONCLUSIONS}

1) The analysis of the pollutant-resistant, the valve under conditions of NAS12 level, continuously operates 5000 times without spool clogging occurs, coils burning anomalies, which is possible to meet the requirements.

2) The leakage test, on the one hand, it can be seen that contamination resistance test of the valve leakage almost have no effect.. On the other hand, the valve leakage minimum, thereby locks the working platform, and protects of the personal safety of the operating personnel.

\section{REFERENCES}

[1] Lei Tianjue New hydraulic engineering manual (up and down) (two), Beijing Institute of Technology Press

[2] Li J Z.1998.Impact calculation of drop hammer towards leg and safety valve system Coal Society,23 (1) :85-87.

[3] Li X X.2001.Research of large flow—rate safety valve of hydraulic support Coal Electro mechanic, (2) :5-6.

[4] Wang Y'2005.Development and prospects of mechanized power support hydraulic control technology Coal Mining, 10 f3) :38-39.

[5] Wang 2007a.Feasibility analysis of a large flow-rate safety valve test bed.CoalMining, 12(5) :6-8.

[6] Du C Lily C X,1989.Optimum design of the large flow-rate safety valve Journal of Shandong Mining Institute,8 (1) :93-94.

[7] JGT5100-1998 scissor type aerial working platform 